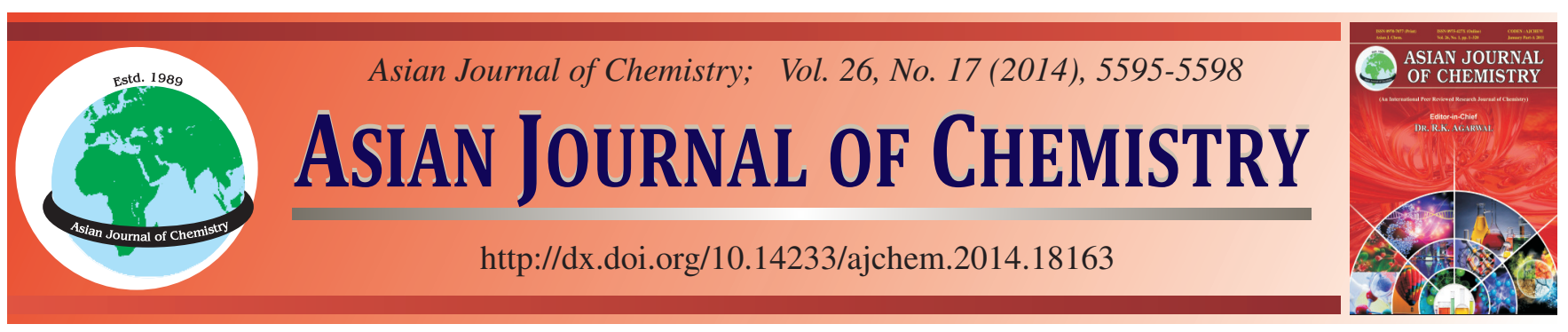

\title{
Preparation and Performance Evaluation of Novel High Durability Epoxy Asphalt Concrete for Bridge Deck Pavements $\dagger$
}

\author{
SANG LuO* and ZHENDONG QIAN
}

Intelligent Transport System Research Center, Southeast University, Nanjing 210096, P.R. China

*Corresponding author: Fax: +86 25 83792869; Tel: +86 13913886226; E-mail: luosangseu@ gmail.com

In this paper, a novel high durability epoxy asphalt concrete for steel deck pavements is introduced, including the manufacturing process of epoxy asphalt binder and laboratory evaluation for this material.A variety of laboratory tests were conducted to evaluate the pavement performance of the materials, such as Brookfield test, direct tension test, fatigue test, wheel tracking test, moisture susceptibility test and thermal stress restrained specimen test. Test results show that epoxy asphalt binder is a hyperelastic material and epoxy asphalt concrete has 20137 cycles $/ \mathrm{mm}$ dynamic stability at $70{ }^{\circ} \mathrm{C}, 90.8 \%$ tensile strength ratio and $-28.4{ }^{\circ} \mathrm{C}$ fracture temperature. The fatigue equations of epoxy asphalt concrete at different temperatures were obtained. It is indicated that the epoxy asphalt concrete is a suitable material for the pavement of long-span steel bridges in China due to its profound performance.

Keywords: Epoxy asphalt, Durability, Bridge deck pavement, Fatigue cracking.

\section{INTRODUCTION}

Bridge deck pavements have been used to protect the steel deck against from moisture damage and ensure good riding quality and skid resistance. However, different types of distress such as cracking and pot holes have been observed in bridge deck pavements ${ }^{1-3,6}$. Repeated load, vibrations of the bridge deck and severe weather conditions accelerate these pavement distresses. Moreover, such deterioration reduces the service life of bridge system and increases repair and rehabilitation $\operatorname{costs}^{4-6}$.

One of the primary modes of destruction in bridge deck pavements is fatigue cracking ${ }^{6}$, which affects the concrete or steel deck durability. The asphalt mixture stiffness and the adhesive bond between the asphalt layer and the bridge deck are decreased by the fatigue cracking and moisture infiltration ${ }^{6}$.

The major objective of this study is to develop a novel high durability epoxy asphalt concrete applicable to steel deck pavements to improve fatigue cracking resistance and moisture-induced cracking ${ }^{6}$. To evaluate the material characteristics, a variety of laboratory tests have been carried out on the developed binder and mix.

\section{EXPERIMENTAL}

Development of a high durability epoxy asphalt binder: Epoxy asphalt binder is a thermosetting material which is one composite by combining epoxy resin (component A) to maleated modified asphalt with curing agent (component B). Component A is E-51 epoxy resin, which is an ordinary product. The manufacturing procedure of component $\mathrm{B}$ is as following. Firstly, maleic anhydride was used to modify the base asphalt to obtain the maleated asphalt, which could be cured by the epoxy resin to improve the compatibility of asphalt and epoxy resin. And then, adipic acid and methylhexahydrophthalic anhydride, as the curing agents, were added into maleated asphalt. Moreover, some accelerants were added to control the curing time. The manufacturing process of component B is shown in Fig. 1.

Mixtures: Epoxy asphalt binder and basalt were used to produce the mixture in this study. A typical dense gradation with a nominal maximum size aggregate of $9.5 \mathrm{~mm}$ was used for the mixture testing ${ }^{6}$. The optimum asphalt aggregate ratio is determined as $6.5 \%$ according to Marshall mix design method. The air voids of all specimens used for testing are controlled at $2.0 \pm 0.2 \%$.

\section{RESULTS AND DISCUSSION}

\section{Epoxy asphalt binder testing}

Brookfield test for viscosity: The rheological property of epoxy asphalt binder during the curing process was measured 


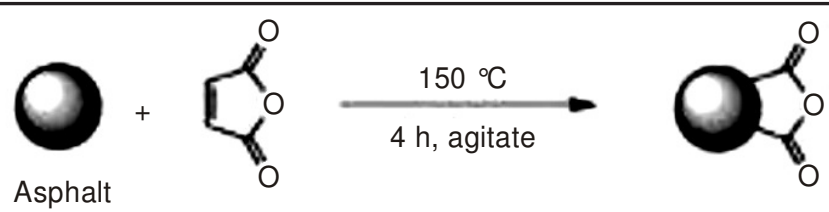

(I) Maleated asphalt
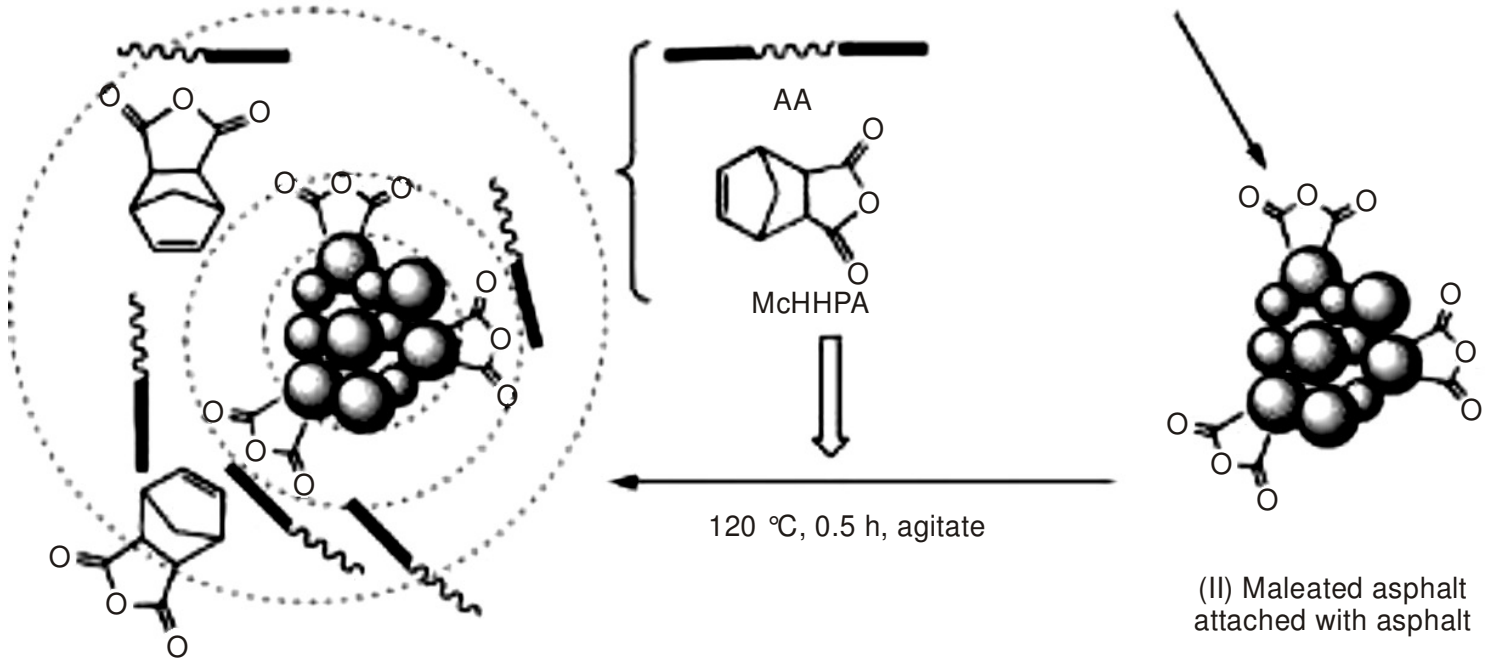

$120{ }^{\circ} \mathrm{C}, 0.5 \mathrm{~h}$, agitate

(II) Maleated asphalt attached with asphalt

(III) Component B

Fig. 1. Manufacturing process of component B

by Brookfield test. The test was carried out according to ASTM D798. The test temperatures were 110, 115, 120, 125 and $130{ }^{\circ} \mathrm{C}$. The viscosity values were recorded every $5 \mathrm{~min}$. The test result is shown in Fig. 2.

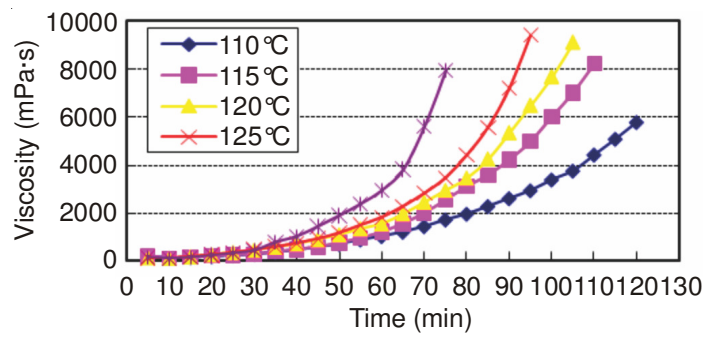

Fig. 2. Viscosity vs. time curve at different temperature

As shown in Fig. 2, the viscosity of epoxy asphalt binder increases with the increment of reaction time and temperature, which is different from thermoplastic asphalt whose viscosity changes only with temperature.

Direct tension test: The direct tension test was conducted for epoxy asphalt binder according to ASTM D638. The dumbbell-shaped specimens with $5.6 \mathrm{~mm}$ thickness were cut from an asphalt plate as shown in Fig. 3. The test temperature of $23^{\circ} \mathrm{C}$ and the elongation rate of $500 \mathrm{~mm} / \mathrm{min}$ were applied in the direct tension test. The stress-strain curve of epoxy asphalt binder is shown in Fig. 4 and the ultimate tensile strength and rupture elongation can be obtained from the test.

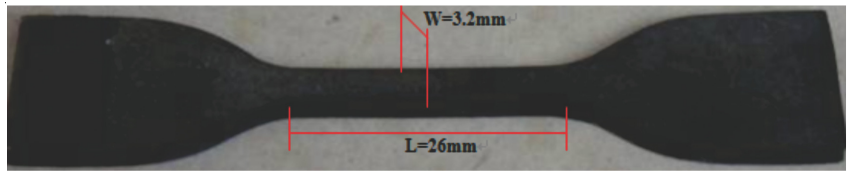

Fig. 3. Dumbbell-shaped specimen for direct tension test

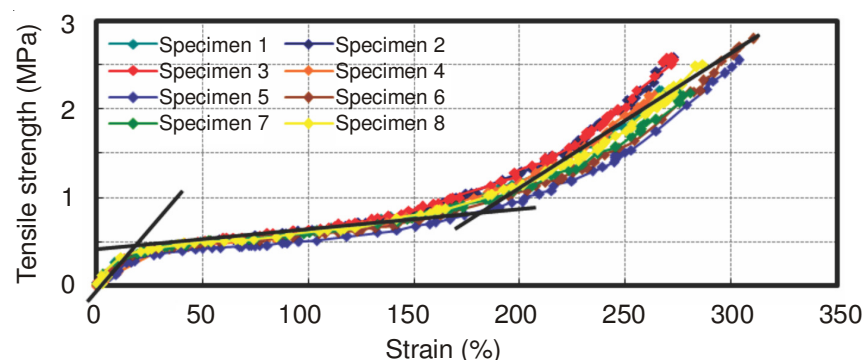

Fig. 4. Stress-strain curves of epoxy asphalt binder at $23{ }^{\circ} \mathrm{C}$

As shown in Fig. 4, it can be concluded that epoxy asphalt binder is hyperelastic material, since the stress-strain curves of epoxy asphalt binder were divided into three non-linear elastic regions. Moreover, epoxy asphalt binder exhibits distinguishable properties with that of conventional asphalt binders in three aspects. Firstly, the stress-strain curves of epoxy asphalt binder do not have apparent yield point no-necking phenomena. Secondly, the large elongation at break is as high as 270-310\%. Thirdly, Young's modulus of epoxy asphalt binder are times higher than that of rubbers, which are 1-10 $\mathrm{MPa}$ according to the definition of ASTM.

\section{Epoxy asphalt mixture testing}

Fatigue testing: Four-points bending fatigue test was performed by the use of servo-hydraulic closed loop testing system according to ASTM. Beam specimens of $381 \mathrm{~mm} \times$ $63.5 \mathrm{~mm} \times 50 \mathrm{~mm}$ were cut from $400 \mathrm{~mm} \times 400 \mathrm{~mm} \times 76 \mathrm{~mm}$ slab fabricated by rolling wheel compaction in the laboratory. The strain-controlled mode was applied in the fatigue tests. All tests were made at $10 \mathrm{~Hz}$ frequency, under sinusoidal loading with no rest periods. The rest temperatures included 10,20 and $30^{\circ} \mathrm{C}$. The three initial strain levels at each test temperature were obtained from FEM simulation with ADINA, 
which are the maximum strain of epoxy asphalt pavement on steel deck bridge under $0.7,1.10$ and $1.40 \mathrm{MPa}$ tire pressures, respectively. According to the calculating results, the 400, 600 and 900 microstrain were used as the initial strain levels at 10 ${ }^{\circ} \mathrm{C}$. The 600, 750 and 900 microstrain were used as the initial strain levels at $20^{\circ} \mathrm{C}$. The 600,900 and 1200 microstrain were used as the initial strain levels at $30^{\circ} \mathrm{C}$. The failure criterion adopted in this test is the number of load repetitions when the current stiffness reduces to $50 \%$ of the original stiffness ${ }^{6}$. The coefficients $\mathrm{a}$ and $\mathrm{b}$ for the fatigue model shown in eqn. 1 were estimated through regression analysis based on the test data $^{6}$.

$$
\mathrm{N}_{\mathrm{f}}=\mathrm{a}(\varepsilon)^{\mathrm{b}}
$$

in which $\mathrm{N}_{\mathrm{f}}$ is the fatigue life of the asphalt mixture; $\varepsilon$ is the initial strain level; a, b are the fatigue coefficients.

Fig. 5 shows the fatigue test results for epoxy asphalt mixtures at different temperatures and initial strain levels. As shown in Fig. 5, epoxy asphalt mixtures exhibit outstanding fatigue performance, since the fatigue life of epoxy asphalt mixture is more than $4.48 \times 10^{6}$ cycles under 600 microstrain at $20^{\circ} \mathrm{C}$. However, according to HeeMun Park's research results ${ }^{6}$, a high durability asphalt mixture for bridge deck pavements has 3.73 $\times 10^{4}$ cycles of fatigue life under 100 microstrain at $20{ }^{\circ} \mathrm{C}$. Table- 1 indicates the coefficients of the fatigue model in eqn. 1 at different test temperatures for epoxy asphalt concrete.

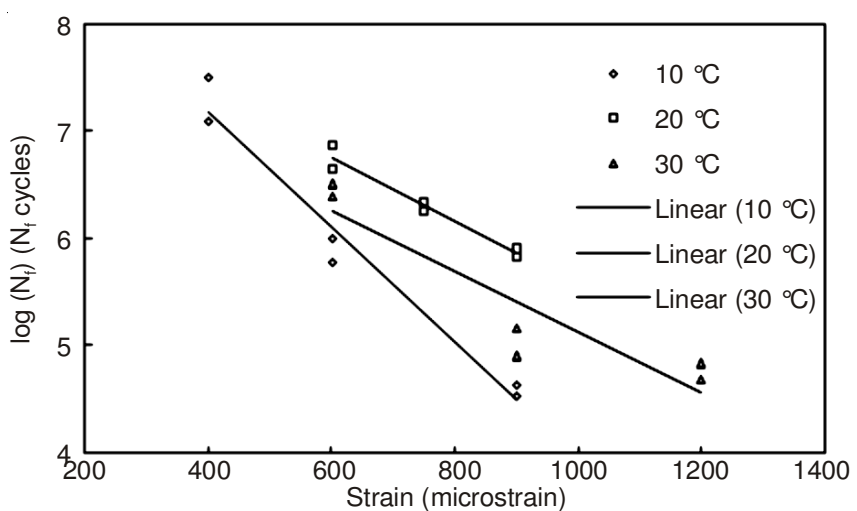

Fig. 5. Fatigue tests for epoxy asphalt mixture at different temperatures and strains

\begin{tabular}{cccc}
\multicolumn{3}{c}{ TABLE-1 } \\
\multicolumn{3}{c}{ COEFFICIENTS OF FATIGUE MODEL } \\
& \multicolumn{2}{c}{ FOR EPOXY ASPHALT CONCRETE } \\
\cline { 2 - 3 } Test temperature $\left({ }^{\circ} \mathrm{C}\right)$ & \multicolumn{2}{c}{ Fatigue coefficients } & \multirow{2}{*}{$\mathrm{R}^{2}$} \\
\cline { 2 - 3 } & $\mathrm{a}$ & $\mathrm{b}$ & \\
\hline 10 & $2 \times 10^{27}$ & -7.7142 & 0.9834 \\
20 & $9 \times 10^{20}$ & -5.1051 & 0.9597 \\
30 & $2 \times 10^{22}$ & -5.7761 & 0.9123 \\
\hline
\end{tabular}

Wheel tracking testing: Wheel tracking test was used to assess the high temperature performance of epoxy asphalt mixture according to JTJ 052-2000 test procedure. A contact pressure of $700 \mathrm{kPa}$ and total wheel load of $1.4 \mathrm{kN}$ were applied to the slab specimens of $300 \mathrm{~mm} \times 300 \mathrm{~mm} \times 50 \mathrm{~mm}$. The 60 and $70^{\circ} \mathrm{C}$ were selected as test temperatures, since $60{ }^{\circ} \mathrm{C}$ is the standard temperature specified by JTJ 052-2000 test procedure and $70{ }^{\circ} \mathrm{C}$ is the highest temperature achieved of bridge deck pavements in China. The wheel rotates 42 times per minute at the center of the specimen and the permanent deformation was measured ${ }^{6}$. Dynamic stability values were obtained from the wheel tracking test data and were shown in Table-2. Test results show that epoxy asphalt concrete has good performance to resistant permanent deformation due to their high dynamic stability.

TABLE-2

RESULTS OF WHEEL TRACKING TEST

\begin{tabular}{ccc}
\hline Mixture & \multicolumn{2}{c}{ Epoxy asphalt concrete } \\
\hline Test temperature $\left({ }^{\circ} \mathrm{C}\right)$ & 60 & 70 \\
Dynamic stability $(\mathrm{cycle} / \mathrm{mm})$ & 20803 & 20137 \\
\hline
\end{tabular}

Moisture susceptibility testing: Moisture-induced cracking is one of primary destructions observed in steel deck pavements. Moisture susceptibility of the mixtures was determined using the AASHTO T 283 test method with some modifications as specified in ASTM D 7064. For moisture conditioned specimens, they were first saturated at a vacuum of $87.8 \mathrm{kPa}$ for $10 \mathrm{~min}$ and then submerged in water during the $16 \mathrm{~h}$ freeze cycle. In $24 \mathrm{~h}$ thaw cycles, specimens were wrapped with plastic tube walls to prevent breakdown of the mixture in the $60{ }^{\circ} \mathrm{C}$ water bath. The dry and wet tensile strengths of epoxy asphalt concrete are shown in Table-3. The tensile strength ratio (TSR) was used to evaluate the resistance to moisture for asphalt mixture. The tensile strength ratio is defined as the tensile strength ratio between the dry and moisture specimens ${ }^{6}$. It is generally known that a higher tensile strength ratio value suggests a better resistance to moisture damage.

\begin{tabular}{ccc}
\multicolumn{3}{c}{ TABLE-3 } \\
\multicolumn{2}{c}{ RESULTS OF MOISTURE SUSCEPTIBILITY TEST } \\
\hline \multirow{2}{*}{ Mixture } & \multicolumn{2}{c}{ Epoxy asphalt concrete } \\
\cline { 2 - 3 } & Indirect strength (MPa) & TSR (\%) \\
\hline Dry condition & 5.87 & \multirow{2}{*}{90.8} \\
Moisture condition & 5.33 & \\
\hline
\end{tabular}

Thermal stress restrained specimen test: In this study, the low temperature cracking resistance of the asphalt mixtures was determined by the thermal stress restrained specimen test $(\text { TSRST })^{7-9}$. The basic principle of the test system is to keep the length of the asphalt sample constant during cooling 9 . A cylindrical specimen is installed in the load frame. The inner temperature of the environmental chamber is decreased during the test with the help of vaporized liquid nitrogen or a refrigerating machine ${ }^{9}$. As the specimen contracted, two linear variable differential transducers (LVDT) sense the movement and a signal is sent to a computer, which in turn caused the screw jack to stretch the specimen back to its original length ${ }^{9}$. As the temperature continued to reduce, thermal stress inside the sample increases until the specimen broke?.

The tests were conducted on epoxy asphalt specimens and SMA specimens using a cooling rate of $10^{\circ} \mathrm{C} / \mathrm{h}$. The typical thermal stress restrained specimen test curves of epoxy asphalt mixture and SMA are illustrated in Fig. 6. And the test results were shown in Table-4.

The result of epoxy asphalt specimens illustrated in Fig. 6 shows that, from the initial test temperature to transition temperature, a comparatively slow and linear increase in thermal stress was observed. Below transition temperature, the thermally 


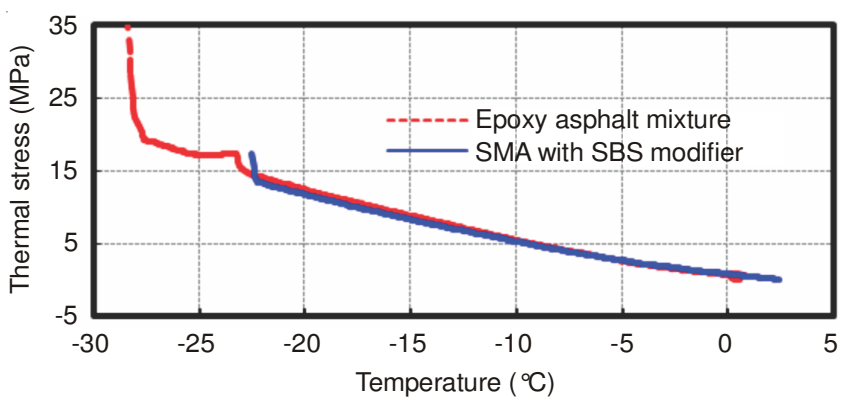

Fig. 6. Typical TSRST test curves of epoxy asphalt mixture and SMA

\begin{tabular}{cccc}
\multicolumn{4}{c}{ TABLE-4 } \\
TSRST RESULTS OF DIFFERENT ASPHALT MIXTURE \\
\hline Mixtures & $\begin{array}{c}\text { Fracture temp. } \\
\left({ }^{\circ} \mathrm{C}\right)\end{array}$ & $\begin{array}{c}\text { Fracture } \\
\text { strength }(\mathrm{MPa})\end{array}$ & $\begin{array}{c}\text { Transition } \\
\text { temp. }\left({ }^{\circ} \mathrm{C}\right)\end{array}$ \\
\hline Epoxy asphalt mixture & -28.4 & 35.4 & -27.8 \\
SMA & -22.6 & 17.3 & -22.1 \\
\hline
\end{tabular}

induced stress has an abrupt and linear increment with temperature. It is found that at the low temperature, epoxy asphalt mixture was similar to the elastic material except for an abrupt increment of the modulus at the transition temperature. As shown in Table-4, the fracture and transition temperatures of epoxy asphalt mixture were lower than those of SMA, while the fracture strength of epoxy asphalt mixture was higher than that of SMA. Findings from the thermal stress restrained specimen test results indicate that epoxy asphalt mixture has better low-temperature performance in comparison with SMA.

Engineering application of novel epoxy asphalt concrete China: Since 2008, the novel epoxy asphalt concrete has been paved on some long-spanned steel deck bridges, including the longest railway-highway combined bridge-Wuhan Tianxingzhou Bridgeas, the longest railway-light rail combined cable bridge-Shanghai Yangtze Bridge and the longest doublelayer cable bridge-Minpu Bridgeshown. The year and area of novel epoxy asphalt concrete are shown in Table-5.

TABLE-5
MAJOR STEEL DECK BRIDGES PAVED WITH
NOVEL EPOXY ASPHALT CONCRETE

\section{Conclusion}

A novel high durability epoxy asphalt concrete for wearing layer of bridge deck pavements were developed in this study. A variety of laboratory tests were conducted to evaluate the performance of the developed material. Primary resulted drawn from this study are summed up as following:

- This novel epoxy asphalt material is sufficient for the bridge deck pavements, with its good performance, including high resistance to fatigue cracking, rutting, moisture damage and low temperature cracking.

- Results of direct tension tests for the epoxy asphalt binder show that epoxy asphalt binder is a hyperelastic material, which is different from thermoplastic material.

- Test results for epoxy asphalt concrete show that it has 20137 cycles/mm dynamic stability at $70{ }^{\circ} \mathrm{C}, 90.8 \%$ tensile strength ratio and $-28.4^{\circ} \mathrm{C}$ fracture temperature.

\section{ACKNOWLEDGEMENTS}

The author is grateful to the Specialized Research Foundation for the Doctoral Program of the Ministry of Education of the People's Republic of China (No. 20110092120062) for their financial support of this work.

\section{REFERENCES}

1. P.E. Sebaaly, A. Lake and J.A. Epps, J. Transp. Eng., 128, 578 (2002).

2. S. Luo, J.W. Wang and Z.D. Qian, In Proceedings of the 26th Southern African Transport Conference, Pretoria, South Africa, pp. 736-744 (2007).

3. W. Huang and Z.D. Qian, Chin. Sci. Bull., 48, 2391 (2003).

4. I.R.C. Widyatmoko, J.M. Elliott and J.M. Read, Road Mater. Pavement, 6, 469 (2005).

5. J.-Y.Yu, P.-C. Feng, H.-L. Zhang and S.-P. Wu, Construct. Build. Mater, 23, 2636 (2009).

6. H.M. Park, J.Y. Choi, H.J. Lee and E.Y. Hwang, Construct. Build. Mater, 23, 219 (2009).

7. T. Wu, Technol. Highway Transport, 2, 32 (2006).

8. S.K. Palit, K.S. Reddy and B.B. Pandey, J. Mater. Civ. Eng., 16, 45 (2004).

9. U. Isacsson and H. Zeng, Construct. Build. Mater., 11, 83 (1997). 